\title{
Comparative transcriptomics reveals key gene expression differences between the human and bovine pathogens of the Mycobacterium tuberculosis complex
}

Correspondence
Stephen Gordon
s.v.gordon@vla.defra.gsi.gov.uk

Received 18 May 2007

Revised 7 June 2007

Accepted 8 June 2007
Paul Golby, ${ }^{1}$ Kim A. Hatch, ${ }^{2}$ Joanna Bacon, ${ }^{2}$ Rory Cooney, ${ }^{1} \dagger$ Paul Riley, ${ }^{2}$ Jon Allnutt, ${ }^{2}$ Jason Hinds, ${ }^{3}$ Javier Nunez, ${ }^{1}$ Philip D. Marsh, ${ }^{2}$ R. Glyn Hewinson ${ }^{1}$ and Stephen V. Gordon ${ }^{1}$

\author{
${ }^{1}$ Veterinary Laboratories Agency (Weybridge), New Haw, Addlestone, Surrey KT15 3NB, UK \\ ${ }^{2}$ Health Protection Agency, Centre for Emergency Preparedness and Response, Porton Down, \\ Salisbury, Wiltshire SP4 OJG, UK \\ ${ }^{3}$ Bacterial Microarray Group, Department of Cellular and Molecular Medicine, St George's Hospital \\ Medical School, Cranmer Terrace, London SW17 ORE, UK
}

\begin{abstract}
Members of the Mycobacterium tuberculosis complex show distinct host preferences, yet the molecular basis for this tropism is unknown. Comparison of the M. tuberculosis and Mycobacterium bovis genome sequences revealed no unique genes in the bovine pathogen per se, indicating that differences in gene expression may play a significant role in host predilection. To define the key gene expression differences between $M$. tuberculosis and M. bovis we have performed transcriptome analyses of cultures grown under steady-state conditions in a chemostat. This revealed that the human and bovine pathogens show differential expression of genes encoding a range of functions, including cell wall and secreted proteins, transcriptional regulators, PE/PPE proteins, lipid metabolism and toxin-antitoxin pairs. Furthermore, we probed the gene expression response of $M$. tuberculosis and $M$. bovis to an acid-shock perturbation which triggered a notably different expression response in the two strains. Through these approaches we have defined a core gene set that shows differential expression between the human and bovine tubercle bacilli, and the biological implications are discussed.
\end{abstract}

\section{INTRODUCTION}

The Mycobacterium tuberculosis complex can be viewed as a set of ecotypes with distinct host preferences (Smith et al., 2006). Hence, while M. tuberculosis can only be sustained in human populations, Mycobacterium bovis can infect and be maintained in populations of wild and domesticated animals such as cattle, deer and badgers. The molecular origin for these phenotypes is encoded in the genomes of the pathogens. The genome sequences of $M$. tuberculosis $\mathrm{H} 37 \mathrm{Rv}$ and M. bovis 2122 are $>99.95 \%$ identical at the nucleotide level, with $M$. bovis containing no unique genes

tPresent address: Veterinary Exotic Diseases, Research and Official Controls Division (VEROD) Defra Area 101, 1a Page Street, London SW1P 4PQ, UK.

Abbreviations: DAT, diacyltrehalose; PAT, polyacyltrehalose; PDIM, phthiocerol dimycoserosate; PGL, phenolic glycolipid; PIN, PilT amino terminus; qRT-PCR, quantitative real-time PCR; TA, toxin-antitoxin.

Supplementary tables of primer sequences used for qRT-PCR reactions, and $M$. bovis and $M$. tuberculosis genes regulated in response to acidshock are available with the online version of this paper. per se compared to M. tuberculosis (Cole et al., 1998; Garnier et al., 2003). Comparative analyses of the $M$. tuberculosis and M. bovis genomes have revealed the basis for distinguishing phenotypes such as the pyruvate requirement of $M$. bovis in glycerol-based media, or the reason for eugonic/dysgonic colony morphology (Keating et al., 2005). However, comparative genomics in itself does not reveal the basis for the complexity of phenotype between M. tuberculosis and M. bovis. Extra information needs to be layered onto the genome data, such as gene expression profiling, metabolic network analyses, signalling pathways, etc., to fully explore the biology of these pathogens.

To explore the hypothesis that transcriptome differences play a role in the differing ecotypes of the M. tuberculosis complex, we set out to define the key gene expression differences between the human and bovine tubercle bacilli. To achieve this, the culture conditions for both organisms must be identical. Clearly, the nature of batch culture makes the system highly dynamic, complicating interpretation of expression profiles. Chemostat systems on the other 
hand allow tight control of bacterial growth in a defined, reproducible system (Hoskisson \& Hobbs, 2005). We therefore chose to define the transcriptomes of the genome sequenced strains M. tuberculosis $\mathrm{H} 37 \mathrm{Rv}$ and M. bovis 2122 under physiological steady-state conditions achieved through growth in carbon-limited chemostat cultures.

During the pathogenic process, M. tuberculosis and $M$. bovis are thought to be exposed to a number of different stress conditions, including acidic $\mathrm{pH}$, reactive nitrogen and oxygen species, and nutrient starvation (Chan et al., 2005). Many of the proteins induced in response to stress are thought to be involved in the survival of the pathogen inside the host. We therefore also chose to study the effect of acid-shock on the steady-state transcriptomes of $M$. tuberculosis and M. bovis as a means to probe the response of both strains to a perturbation.

Hence, the aim of this study was to identify key gene expression differences between M. tuberculosis H37Rv and M. bovis 2122 under both steady-state and perturbation conditions. We found that the expression of genes encoding a range of functional activities varied between the strains, and we discuss the possible biological impact of this variation on strain phenotype.

\section{METHODS}

Bacterial strains and growth conditions. For the continuous culture experiments, M. tuberculosis $\mathrm{H} 37 \mathrm{Rv}$ and M. bovis AF2122 were grown at $37^{\circ} \mathrm{C}$ in defined minimal medium, CAMR Mycobacteria Media (CMM) Mod6 ( $\mathrm{pH} 7.0$ ), at a dissolved oxygen tension of $10 \%$ ( $50 \%$ air saturation), using the approach described previously for $M$. tuberculosis H37Rv (Bacon et al., 2004). CMM Mod6 was a modified version of CMM (James et al., 2000) in which all amino acids were removed except for L-asparagine. Glycerol and glucose were omitted and Tween $80(0.2 \%, \mathrm{v} / \mathrm{v})$ was included as sole carbon source. As is standard practice, BSA $(0.5 \% \mathrm{w} / \mathrm{v})$ was included to ameliorate the toxic side effects of Tween 80 degradation. The cultures were performed in 11 glass fermentation vessels, which were operated as chemostats by controlling medium addition and effluent removal to maintain a working volume of $500 \mathrm{ml}$. The chemostats were operated at a constant dilution rate of $0.03 \mathrm{~h}^{-1}$, which corresponds to a mean generation time of $23 \mathrm{~h}$. The cultures were maintained at a constant $\mathrm{pH} 7.0 \pm 0.1$ and a temperature of $37{ }^{\circ} \mathrm{C} \pm 0.1$. Cultures were monitored for viability by measuring optical density at $540 \mathrm{~nm}$ and total viable count as described by Bacon et al. (2004).

Acid-shock experiments. Acid-shock studies were performed in a chemostat. Three independent aerobic steady-state cultures of $M$. tuberculosis and M. bovis were established at $\mathrm{pH} 7.0$, then when the $\mathrm{pH}$ had dropped to 5.5 the samples were rapidly removed for transcriptome analysis. At the start of each $\mathrm{pH}$ perturbation experiment, maximum and minimum $\mathrm{pH}$ levels were set on the controller unit in the range of $\mathrm{pH} 5.48-5.52$. $\mathrm{HCl}(1 \mathrm{M})$ was automatically added dropwise to the culture until the desired $\mathrm{pH}$ of the culture was reached, i.e. $\mathrm{pH}$ 5.5. The addition of the first drop of acid was taken as time point zero and the time taken for the $\mathrm{pH}$ to fall from 7.0 to 5.5 was in the range of 2.5 to $5 \mathrm{~min}$. The culture was then maintained at pH 5.5 via the automatic addition of $1 \mathrm{M} \mathrm{NaOH}$ or $1 \mathrm{M} \mathrm{HCl}$. Samples $(20 \mathrm{ml})$ were rapidly withdrawn from the culture at 5, 15, 30, $60 \mathrm{~min}$ and $24 \mathrm{~h}$ after time point zero and RNA was extracted as described previously (Bacon et al., 2004). Residual DNA was removed with the use of a DNAfree kit (Ambion) and the integrity of the RNA was checked by non-denaturing gel electrophoresis.

M. tuberculosis-M. bovis microarrays. The M. tuberculosis-M. bovis composite microarrays used in these experiments were developed by the Bacterial Microarray Group (B $\mu \mathrm{G} @ S$, St Georges, University of London) in collaboration with the Veterinary Laboratories Agency (Weybridge). The array consists of 4410 PCR products (size range $60-1000 \mathrm{bp}$ ) that represent all the genes in the genomes of M. tuberculosis strains H37Rv and CDC1551 and M. bovis strain AF2122. Primer pairs for each ORF were designed with Primer 3 software and selected by BLAST analysis to have minimal crosshomology with all other ORFs. PCR products were generated and purified with the aid of a RoboAmp 4200 robot (MWG Biotech) and arrayed in duplicate onto UltraGap aminosilane-coated glass slides (Corning) by a Biorobotics Microgrid II microarrayer (Genomic Solutions). The quality of spots on the microarrays was evaluated using the Spot Check kit (Genetix Ltd). The array design is available in B $\mu \mathrm{G} @$ Sbase, accession no. A-BUGS-31 (http://bugs.sgul.ac.uk/ A-BUGS-31) and also ArrayExpress, accession no. A-BUGS-31.

cDNA labelling and microarray hybridizations. The method used to synthesize labelled cDNA probes from RNA was similar to that described previously with some modifications (Stewart et al., 2002). Complementary DNA synthesized from RNA was fluorescently labelled in a reverse transcription reaction in the presence of Cy5CTP (Amersham Biosciences). In a total volume of $16 \mu$ l, RNA (3$5 \mu \mathrm{g}$ ) was mixed with $5 \mu \mathrm{g}$ random hexamers, heated to $70{ }^{\circ} \mathrm{C}$ for $10 \mathrm{~min}$ and then snap-cooled on ice. To the chilled mixture, $6 \mu \mathrm{l} 5 \times$ first strand buffer, $3 \mu \mathrm{l} 100 \mathrm{mM}$ DTT, $15 \mathrm{nmol}$ each of dATP, dGTP and dTTP, $6 \mathrm{nmol}$ dCTP and $2.5 \mathrm{nmol}$ Cy5-dCTP (Amersham Biosciences) were added. The labelling reaction was initiated by the addition of 400 units of Superscript II (Life Technologies), and the reactions were incubated for $10 \mathrm{~min}$ at $25{ }^{\circ} \mathrm{C}$ and then for $90 \mathrm{~min}$ at $42{ }^{\circ} \mathrm{C}$.

cDNA synthesized using DNA as template was fluorescently labelled using Cy3-dCTP (Amersham Bioscience) and Klenow DNA polymerase. DNA $(3 \mu \mathrm{g})$ was mixed with $3 \mu \mathrm{g}$ random primers in a total volume of $41.5 \mu \mathrm{l}$, heated at $95{ }^{\circ} \mathrm{C}$ for $5 \mathrm{~min}$ and then cooled on ice. To the cooled mixture, $5 \mu \mathrm{l} 10 \times$ Klenow buffer, $5 \mathrm{nmol}$ each of dATP, dGTP and dTTP, 2 nmol dCTP and $1.5 \mathrm{nmol} \mathrm{Cy3-dCTP} \mathrm{were}$ added. The labelling reaction was initiated by the addition of 5 units Klenow fragment of DNA polymerase (New England Biolabs) and the reaction was incubated at $37{ }^{\circ} \mathrm{C}$ for $1.5 \mathrm{~h}$. The Cy5- and Cy3-labelled cDNAs from the labelling reactions were co-purified in water using a mini elute purification kit (Qiagen). The volume of the purified labelled cDNAs was adjusted to $60 \mu \mathrm{l}$ in $4 \times$ SSC and $0.3 \%$ SDS. Prior to use, the microarrays were prehybridized at $65{ }^{\circ} \mathrm{C}$ for $20 \mathrm{~min}$ in $50 \mathrm{ml}$ of a solution containing $3.5 \times$ SSC, $0.1 \%$ SDS and $10 \mathrm{mg} \mathrm{BSA} \mathrm{m}{ }^{-1}$. The slides were washed at room temperature with $\mathrm{H}_{2} \mathrm{O}$ for $1 \mathrm{~min}$, propan-2-ol for $1 \mathrm{~min}$ and then dried by centrifugation. The labelled cDNAs were heated for $3 \mathrm{~min}$ at $95{ }^{\circ} \mathrm{C}$, before being applied to the array under two $22 \times 22 \mathrm{~mm}$ coverslips (LifterSlip; Erie Scientific).

Scanning and image analysis. Hybridized arrays were scanned using an Affymetrix 428 scanner with the photomultiplier tube gain set in the range $40-50$, so that spots with the highest signal intensities were just below the level of saturation; this generated two images per microarray (one per channel) in TIF format. Fluorescent spots on each scanned image were quantified using Imagene 5.1 (Biodiscovery) using a segmentation signal percentage set to a high of $95 \%$ and a low of $5 \%$. The signal for each spot was taken as the median of all pixel intensities within the defined area of the spot. Genomic DNA from $M$. tuberculosis was hybridized in the $\mathrm{Cy} 3$ channel, and was used as a common reference for all arrays. 
Data normalization and statistical analysis. Data processing employed Mathematica Version 5.2 (Wolfram Research). For each channel background, values were first subtracted from signal values for each spot and values less than 0.01 were set to 0.01 . For each microarray the $\log$ ratio of the Cy5 to Cy3 signal was calculated for every spot; each log ratio was then divided by the median of the log ratios of the microarray so as to centre the gene expression distributions of the whole set of microarrays to the same point (zero). After this step the microarrays for the M. bovis acid-shock experiment presented a similar scale; however, some of the arrays for the M. tuberculosis acid-shock data showed a wider distribution. To set all arrays to a common scale, a median absolute deviation scale transformation was therefore applied. As a final normalization step, duplicate spots for each gene on every microarray were averaged, and then the means of every gene across all technical replicate microarrays were calculated.

Means of the three biological replicates were used to compare gene expression between time points. Genes whose mean normalized expression value was larger than threefold different in one or more samples collected after the addition of acid compared to the zero time point sample were selected. A $t$ test with a significance of 0.05 and with the Benjamini Hochberg correction was applied to verify statistical differential expression; those genes verifying this latter requirement were selected for further study. Files containing normalized data were imported into GeneSpring 7.1 (Silicon Genetics) for a graphical representation of the microarray data. Fully annotated microarray data has been deposited in B $\mu \mathrm{G} @$ Sbase (http://bugs.sgul.ac.uk/; accession no. E-BUGS-37) and ArrayExpress (www.ebi.ac.uk/arrayexpress/; accession no. E-BUGS-37).

Quantitative real-time PCR (qRT-PCR). In a total volume of $10 \mu$, RNA $(0.5-1.0 \mu \mathrm{g})$ was mixed with $3 \mu \mathrm{g}$ random hexamers, heated to $70{ }^{\circ} \mathrm{C}$ for $10 \mathrm{~min}$ and then snap-cooled on ice. To the chilled mixture, $4 \mu \mathrm{l} 5 \times$ first strand buffer, $2 \mu \mathrm{l} 100 \mathrm{mM}$ DTT, and $20 \mathrm{nmol}$ each of dATP, dCTP, dGTP and dTTP were added. The labelling reaction was initiated by the addition of 400 units Superscript II, and the reactions were incubated for $10 \mathrm{~min}$ at $25{ }^{\circ} \mathrm{C}$ and then for $90 \mathrm{~min}$ at $42{ }^{\circ} \mathrm{C}$. The synthesized cDNA was purified with a DNA Clean and Concentrator kit (Zymo Research) and serial dilutions of the purified cDNA were made. qRT-PCR reactions were performed using the QuantiTect SYBR Green PCR kit (Qiagen) in a total volume of $25 \mu \mathrm{l}$ containing $5 \mu \mathrm{l}$ diluted cDNA, $12.5 \mu \mathrm{l} 2 \times$ QuantiTect Master Mix and $0.5 \mu \mathrm{l}$ gene-specific primers. PCR amplification was performed using a RotorGene 3000 (Corbett Research) and a programme consisting of 1 cycle at $95{ }^{\circ} \mathrm{C}$ for $15 \mathrm{~min}$, and then $40-50$ cycles at $95{ }^{\circ} \mathrm{C}$ for $15 \mathrm{~s}$ (denaturation), $55{ }^{\circ} \mathrm{C}$ for $30 \mathrm{~s}$ (extension step) and $80{ }^{\circ} \mathrm{C}$ for $30 \mathrm{~s}$ (signal acquisition). Melting curve analysis and gel electrophoresis were performed to confirm the specificity of the qRTPCR products. The sequences of the gene-specific primer pairs were designed to show minimal cross-hybridization to all other genes within the genome. Sequences of the primer pairs are listed in supplementary Table S1 (available with the online version of the journal). The relative expression of each of the genes was normalized to sigA.

\section{RESULTS AND DISCUSSION}

\section{Establishing continuous cultures of $M$. tuberculosis and $M$. bovis}

A key issue in setting up the culture system was the choice of carbon source. Previously in batch culture, glycerol has been used as the carbon source for M. tuberculosis, and pyruvate has been used for M. bovis; clearly, comparative transcriptome profiling required both strains to be grown on the same carbon source, so neither glycerol nor pyruvate were used in this study. Instead, we exploited the presence of the oleic acid ester, Tween 80, in mycobacterial liquid media where it acts as a detergent to ensure dispersed growth; however, it can also be used as a carbon source by mycobacteria (Dubos \& Davis, 1946). Tween $80(0.2 \%, \mathrm{v} / \mathrm{v}$, in water) was therefore used as sole carbon source. The composition of the medium was manipulated to ensure that Tween 80 was the growthlimiting nutrient, and this was confirmed by adding a pulse of Tween $80(0.4 \%, \mathrm{v} / \mathrm{v})$ to the steady-state cultures which resulted in an increase in $\mathrm{OD}_{540}$ over $48 \mathrm{~h}$ from 1.05 to 1.50 for the M. bovis culture, and from 1.325 to 1.55 for the M. tuberculosis culture. Hence, as well as its action as a detergent to prevent clumping, Tween 80 can be used as a carbon source by both $M$. tuberculosis and M. bovis under continuous culture conditions.

Cultures of M. tuberculosis and M. bovis were maintained in steady-state at a dissolved oxygen tension of $10 \%$ (equivalent to $50 \%$ air saturation) at a dilution rate of $0.03 \mathrm{~h}^{-1}$, giving a constant mean generation time of $23 \mathrm{~h}$. The mean $\mathrm{OD}_{540}$ and viable counts for three M. bovis cultures (Mb1-3) under steady-state conditions were, respectively, as follows: Mb1, 0.95 and $3.4 \times$ $10^{8}$ c.f.u. $\mathrm{ml}^{-1} ; \mathrm{Mb} 2,0.8$ and $3.5 \times 10^{8}$ c.f.u. $\mathrm{ml}^{-1}$; $\mathrm{Mb} 3$, 1.16 and $1.8 \times 10^{8}$ c.f.u. $\mathrm{ml}^{-1}$. Mean $\mathrm{OD}_{540}$ and viable counts for three M. tuberculosis cultures (Mtb1-3) under steady-state conditions were, respectively, as follows: Mtb1, 1.29 and $3.7 \times 10^{8}$ c.f.u. $\mathrm{ml}^{-1} ; \quad \mathrm{Mtb} 2, \quad 1.23$ and $3.9 \times 10^{8}$ c.f.u. $\mathrm{ml}^{-1}$; Mtb3, 1.32 and $3.1 \times 10^{8}$ c.f.u. $\mathrm{ml}^{-1}$.

\section{Differential gene expression in M. tuberculosis H37Rv and M. bovis AF2122 during steady-state growth}

Ninety-two genes were identified that showed a minimum of threefold differential expression between M. bovis and $M$. tuberculosis during steady-state growth in continuous culture. Forty-three M. bovis genes showed higher expression than their M. tuberculosis orthologues, while 49 genes showed higher expression in M. tuberculosis (Tables 1 and 2 , respectively). To focus our discussion we highlight differences in the key categories of cell wall and secreted proteins, lipid metabolism, gene regulators, PE/PPE family, and toxin-antitoxin (TA) gene pairs, and examine the potential role of these variably expressed genes in phenotypic differences between the human and bovine bacilli.

\section{Cell wall and secreted proteins}

Two of the most highly expressed genes in M. bovis compared to their orthologues in $M$. tuberculosis were $m p b 83$ and $m p b 70$, encoding the serodominant antigens MPB83 and MPB70 which have been shown to be the major protein differences between $M$. tuberculosis and $M$. 
Table 1. Genes expressed at higher levels in $M$. bovis than $M$. tuberculosis under steady-state growth

\begin{tabular}{|c|c|c|c|c|}
\hline \multicolumn{2}{|c|}{ Coding sequence } & \multirow{2}{*}{$\begin{array}{l}\text { Gene } \\
\text { name }\end{array}$} & \multirow{2}{*}{$\begin{array}{l}\text {-Fold } \\
\text { change }\end{array}$} & \multirow[t]{2}{*}{ Product } \\
\hline $\begin{array}{c}\text { M. bovis } \\
2122\end{array}$ & $\begin{array}{c}\text { M. tuberculosis } \\
\text { H37Rv }\end{array}$ & & & \\
\hline Mb0066 & $R v 0065$ & vapC-1 & 6.6 & PIN domain protein \\
\hline$M b 0222$ & $R v 0216$ & & 17.7 & Acyl-CoA hydrolase \\
\hline$M b 0223 c$ & $R v 0217 c$ & lipW & 5.8 & Esterase \\
\hline$M b 0454 c$ & $R v 0446 c$ & & 4.1 & Conserved hypothetical protein \\
\hline$M b 0455 c$ & $R v 0447 c$ & $u f a A 1$ & 3.6 & Fatty acid synthase \\
\hline$M b 0456 c$ & $R v 0448 c$ & & 5.2 & Conserved hypothetical protein \\
\hline$M b 0457 c$ & $R v 0449 c$ & & 13.7 & Putative amine oxidase \\
\hline$M b 0474 c$ & $R v 0465 c$ & & 3.8 & Putative transcriptional regulator \\
\hline$M b 0563 c$ & $R v 0549 c$ & vapC-3' & 3.5 & Truncated PIN domain protein \\
\hline$M b 0607$ & $R v 0592$ & $m c e 2 D$ & 4.8 & Mce family protein \\
\hline Mb0635 & $R v 0619$ & galTb & 3.6 & Galactose uridyltransferase \\
\hline Mb0792 & $R v 0769$ & & 3.4 & Probable short-chain dehydrogenase \\
\hline$M b 0804$ & $R v 0782$ & $p t r B b$ & 7.4 & Probable protease II \\
\hline$M b 1405$ & $R v 1371$ & & 5.2 & Conserved transmembrane protein \\
\hline$M b 1529$ & $R v 1492$ & mutA & 3.3 & Probable methylmalonyl-CoA mutase \\
\hline$M b 1649 c$ & $R v 1623 c$ & $c y d A$ & 5.2 & Probable cytochrome oxidase \\
\hline$M b 2003 c$ & $R v 1981 c$ & $n r d F 1$ & 7.0 & Ribonucleotide reductase small subunit \\
\hline$M b 2050 c$ & $R v 2025 c$ & & 4.4 & Transmembrane protein \\
\hline Mb2095 & $R v 2069$ & $\operatorname{sig} C$ & 3.2 & RNA polymerase sigma factor \\
\hline$M b 2651$ & $R v 2618$ & & 4.1 & Possible transcriptional regulator \\
\hline$M b 2652 c$ & $R v 2619 c$ & & 8.6 & Conserved hypothetical protein \\
\hline$M b 2653 c$ & $R v 2620 c$ & & 15.2 & Conserved transmembrane protein \\
\hline$M b 2654 c$ & $R v 2621 c$ & & 13.6 & Possible transcriptional regulator \\
\hline$M b 2655$ & $R v 2622$ & & 12.5 & Possible methyltransferase \\
\hline$M b 2898$ & $R v 2873$ & $m p b 83$ & 60.3 & Cell surface lipoprotein \\
\hline$M b 2899$ & $R v 2874$ & $\operatorname{dip} Z$ & 34.3 & CcdA-like membrane protein \\
\hline$M b 2900$ & $R v 2875$ & $m p b 70$ & 63.4 & Secreted immunogenic lipoprotein \\
\hline$M b 2901$ & $R v 2876$ & & 7.8 & Transmembrane protein \\
\hline$M b 2902 c$ & $R v 2877 c$ & & 21.4 & Membrane protein \\
\hline$M b 2970 c$ & $R v 2945 c$ & $\operatorname{lpp} X$ & 3.8 & PDIM export protein \\
\hline$M b 2971 c$ & $R v 2946 c$ & pks1 & 3.5 & PDIM synthesis \\
\hline$M b 2982 c$ & $R v 2958 c$ & & 3.9 & PGL and $p$-hydroxybenzoic acid biosynthesis \\
\hline$M b 3012 c$ & $R v 2988 c$ & leuC & 3.5 & Leucine synthase \\
\hline$M b 3109 c$ & $R v 3082 c$ & virS & 10.2 & Transcriptional regulator \\
\hline$M b 3379 c$ & $R v 3347 c$ & PPE55 & 4.0 & PPE family protein \\
\hline$M b 3427 c$ & $R v 3395 c$ & & 5.4 & Conserved hypothetical protein \\
\hline$M b 3477 c$ & $R v 3447 c$ & & 8.6 & FtsK/SpoIIIE family \\
\hline$M b 3706 c$ & $R v 3681 c$ & whiB4 & 10.7 & Possible transcriptional regulator \\
\hline$M b 3829 c$ & $R v 3862 c$ & whiB6 & 4.4 & Possible transcriptional regulator \\
\hline Mb3894 & $R v 3864$ & & 4.7 & Conserved hypothetical protein \\
\hline Mb3902 & Rv3872 & PE35 & 3.9 & PE family protein \\
\hline Mb3903 & $R v 3873$ & PPE68 & 3.8 & PPE family protein \\
\hline Mb3904 & $R v 3874$ & $e s x B$ & 4.5 & ESAT-6 antigen \\
\hline
\end{tabular}

bovis (Hewinson et al., 1996). Using a combination of expression profiling and comparative genomics, Behr and colleagues have shown that the inactivation of a negative regulator is the basis for high expression in $M$. bovis (Charlet et al., 2005; Said-Salim et al., 2006). Hence, expression of $m p b 83$ and $m p b 70$ is controlled by an antisigma factor/sigma factor pair, RskA/SigK; a mutation in the RskA (Mb0452c) anti-sigma factor in M. bovis prevents repression of SigK activity, leading to constitutive $m p b 70$ and $m p b 83$. Another animal-adapted member of the $M$. tuberculosis complex, the 'oryx' bacillus (Mostowy et al., 2005; van Soolingen et al., 1994), is also a high producer of MPB70 and MPB83, and has an independent mutation in RskA that abolishes its activity (Said-Salim et al., 2006). 
These independent mutations would suggest positive selection for overexpression of MPB70 and MPB83 in M. bovis and the oryx bacillus, the phenotypic advantage of which remains to be determined. The genes $M b 0455 c$, $M b 0456 c, M b 0457 c, \operatorname{dipZ}, M b 2901$ and $M b 2902 c$ are also part of the SigK regulon, and show higher expression in $M$. bovis than in M. tuberculosis; however, as with MPB83 and MPB70, the precise functions of their encoded proteins are unknown.

Rv0987 and Rv0988 encode part of an ABC transporter and a putative secreted hydrolase, respectively. Both genes showed higher expression in $M$. tuberculosis H37Rv (Table 2), and in M. bovis 2122 the Rv0987 orthologue is frameshifted (Mb1013/Mb1014). Inactivation of $R v 0987$ in $M$. tuberculosis reduces the ability of the mutant to bind to THP-1 macrophages, but does not reduce virulence in the mouse model (Rosas-Magallanes et al., 2007). An Rv0987 mutant was also found to be incapable of invasion across the blood-brain barrier (Jain et al., 2006). Whether mutation and decreased expression of the M. bovis Rv0987-0988 orthologues reflect inactivation of factors no longer needed for full virulence of the bovine bacillus remains to be verified.

\section{Lipid metabolism}

Sulfolipid is a trehalose-containing sulfatide which is absent from M. bovis, but present in M. tuberculosis. It is therefore not surprising that the mmpL8-papA1-pks2 locus responsible for sulfolipid synthesis (Bhatt et al., 2007; Converse et al., 2003; Sirakova et al., 2001) showed approximately fourfold higher expression in M. tuberculosis (Table 2). The cluster $p k s 4-R v 1184 c-R v 1185 c$ involved in the synthesis of another group of non-mycolated trehalose esters, the diacyltrehalose (DAT) and polyacyltrehaloses (PATs) (Dubey et al., 2002), also showed higher expression in M. tuberculosis (Table 2). Both of these gene clusters have been shown to be under control of the PhoPR regulon (Gonzalo Asensio et al., 2006; Walters et al., 2006). It is therefore interesting that phoR contains two non-synonymous single nucleotide polymorphisms in $M$. bovis, with glycine at position 71 of the M. tuberculosis PhoR replaced by isoleucine in M. bovis and proline-172 replaced by leucine. Hence, mutation of PhoR may lead to the divergent expression of sulfolipid, DAT and PAT biosynthetic genes in M. bovis.

M. bovis showed higher expression of the lppX-pks1 pair, which are involved in the transport (Sulzenbacher et al., 2006) and synthesis (Constant et al., 2002) of phthiocerol dimycoserosate (PDIM), respectively (Table 1). TLC analyses did not reveal significant differences in PDIM production between M. bovis 2122 and M. tuberculosis $\mathrm{H} 37 \mathrm{Rv}$ (data not shown), suggesting the expression difference may relate to the synthesis of the PDIM-derived mycoside B by $M$. bovis, a glycolipid which is lacking in $M$. tuberculosis H37Rv. Rv2958c, encoding a glycosyltransferase involved in the synthesis of the trisaccharide phenolic glycolipid (PGL) that is derived from PDIM, was also found to be expressed at higher levels in M. bovis (Table 1). PGL is not produced by $M$. tuberculosis $\mathrm{H} 37 \mathrm{Rv}$, so the higher expression of this gene in $M$. bovis may simply be down to low expression of the synthetic pathways in $M$. tuberculosis. However, it should also be noted that Rv2958c is non-functional in M. bovis, so the higher expression of its gene may simply be due to loss of negative feedback inhibition. As the regulation of PDIM and PGL synthesis is currently poorly understood, comparisons between $M$. bovis and $M$. tuberculosis offer an ideal starting point to tease the system apart.

Mb0222 showed 17-fold higher expression in M. bovis compared with the M. tuberculosis orthologue Rv0216, with the adjacent lipW also up-regulated (Table 1). The similarity of Mb0222 to acyl dehydratases, and its location close to genes encoding a fatty acyl-CoA ligase $(\mathrm{Mb0220c})$, an acyl dehydrogenase $(\mathrm{Mb0221c})$ and an esterase $(\mathrm{Mb0223c})$, indicates a role in fatty acid catabolism. $R v 0216$ has been shown to be required for virulence in $M$. tuberculosis (Sassetti \& Rubin, 2003), while Mycobacterium leprae has retained a functional orthologue, ML2625 (Cole et al., 2001); the M. bovis orthologue may also, therefore, play a role in virulence. Up-regulation of Mb0222 may indicate that the encoded product is primed for immediate activity on $M$. bovis entering the host.

\section{Gene regulators}

Transcriptional regulators that showed variable expression were Mb2651, Mb2654c, Mb3109c/virS, Mb3477c (expressed at higher levels in M. bovis; Table 1), and Rv0196, Rv0275c and Rv2160A-Rv2160c (higher in M. tuberculosis; Table 2). The latter gene pair, $R v 2160 A-R v 2160 c$, are frameshifted in $M$. tuberculosis $\mathrm{H} 37 \mathrm{Rv}$, with the intact orthologue in $M$. bovis $(\mathrm{Mb2184c})$ showing similarity to TetR-family transcriptional repressors. As the flanking genes $R v 2159 c$ and $R v 2161 c$ also show higher expression in M. tuberculosis $\mathrm{H} 37 \mathrm{Rv}$, it suggests that loss of the repressor from $M$. tuberculosis leads to up-regulation of this locus.

Mb3706c/whiB4 and Mb3829c/whiB6 were expressed at higher levels in M. bovis 2122 (Table 1). The WhiB family were originally designated as transcription factors based on the presence of putative DNA-binding motifs (Davis \& Chater, 1992), but direct proof for this activity is lacking. Recent work has shown that this family bind Fe-S clusters (Jakimowicz et al., 2005), and indeed WhiB4 binds $\mathrm{Fe}-\mathrm{S}$ and functions as a disulfide reductase (Alam et al., 2007). Furthermore, comparing expression of all seven whiB genes in $M$. tuberculosis to a range of stress conditions, Bishai and colleagues found that whiB6 expression was the most stress-responsive (Geiman et al., 2006). The WhiB proteins of tubercle bacilli may therefore function in redox signalling during oxidative and nitrosative stress, conditions which prevail in the in vivo milieu. Up-regulation of whiB4 and whiB6 in M. bovis under in vitro conditions may therefore indicate an increased need to sense and respond quickly to oxidative stress. 
Table 2. Genes expressed at higher levels in M. tuberculosis than M. bovis under steady-state growth

\begin{tabular}{|c|c|c|c|c|}
\hline \multicolumn{2}{|c|}{ Coding sequence } & \multirow{2}{*}{$\begin{array}{l}\text { Gene } \\
\text { name }\end{array}$} & \multirow{2}{*}{$\begin{array}{l}\text {-Fold } \\
\text { change }\end{array}$} & \multirow[t]{2}{*}{ Product } \\
\hline $\begin{array}{c}\text { M. tuberculosis } \\
\text { H37Rv }\end{array}$ & M. bovis 2122 & & & \\
\hline$R v 0120 c$ & $M b 0124 c$ & fusA2 & 3.1 & Translation elongation factor \\
\hline$R v 0196$ & Mb0202 & & 3.5 & Putative transcriptional regulator \\
\hline$R v 0197$ & Mb0203 & & 5.5 & Possible oxidoreductase \\
\hline$R v 0275 c$ & $M b 0281 c$ & & 4.8 & Putative transcriptional regulator \\
\hline$R v 0276$ & $M b 0282$ & & 12.0 & Conserved hypothetical protein \\
\hline Rv0557 & $M b 0572$ & $\operatorname{pim} B$ & 3.8 & Mannosyltransferase \\
\hline$R v 0933$ & $M b 0958$ & $p s t B$ & 3.1 & ABC-type phosphate transport system \\
\hline$R v 0934$ & Mb0959 & pstS1 & 5.0 & Phosphate binding lipoprotein \\
\hline Rv0987 & Mb1013; Mb1014 & & 5.1 & ABC-type transport system \\
\hline Rv0988 & Mb1015 & & 3.8 & Secreted hydrolase \\
\hline$R v 1161$ & $M b 1193$ & narG & 4.0 & Nitrate reductase subunit \\
\hline$R v 1162$ & $M b 1194$ & narH & 10.8 & Nitrate reductase subunit \\
\hline$R v 1181$ & $M b 1213$ & $p k s 4$ & 4.4 & DAT and PAT synthesis \\
\hline$R v 1184 c$ & $M b 1216 c$ & & 7.8 & DAT and PAT synthesis \\
\hline$R v 1185 c$ & $M b 1217 c$ & fadD21 & 3.7 & DAT and PAT synthesis \\
\hline$R v 1186 c$ & $M b 1218 c$ & & 5.6 & Conserved hypothetical protein \\
\hline$R v 1374 c$ & $M b 1409 c$ & & 3.3 & Conserved hypothetical protein \\
\hline$R v 1397 c$ & $M b 1432 c$ & & 4.2 & Conserved hypothetical protein \\
\hline$R v 1398 c$ & $M b 1433 c$ & & 7.8 & Conserved hypothetical protein \\
\hline$R v 1535$ & $M b 1562$ & & 4.5 & Conserved hypothetical protein \\
\hline$R v 1595$ & $M b 1621$ & $n a d B$ & 3.1 & NAD synthase \\
\hline$R v 1596$ & $M b 1622$ & nadC & 4.7 & NAD synthase \\
\hline$R v 1809$ & $M b 1838 ; M b 1839$ & PPE33 & 3.3 & PPE family protein \\
\hline$R v 1810$ & $M b 1840$ & & 3.6 & Conserved hypothetical protein \\
\hline$R v 1899 c$ & $M b 1934 c$ & $l p p D$ & 5.2 & Lipoprotein \\
\hline$R v 1925$ & $M b 1960$ & fadD31 & 4.1 & Fatty acid synthase \\
\hline$R v 2077 c$ & $M b 2102 c$ & & 10.2 & Transmembrane protein \\
\hline$R v 2159 c$ & $M b 2183 c$ & & 21.8 & Alkylhydroperoxidase-like protein \\
\hline$R v 2160 A$ & $M b 2184 c$ & & 8.4 & Conserved hypothetical protein \\
\hline$R v 2160 c$ & $M b 2184 c$ & & 12.7 & Conserved hypothetical protein \\
\hline$R v 2161 c$ & $M b 2185 c$ & & 20.2 & Flavin-dependent oxidoreductase \\
\hline$R v 2331$ & $M b 2358$ & & 6.9 & Conserved hypothetical protein \\
\hline$R v 3094 c$ & $M b 3121 c$ & & 3.4 & Conserved hypothetical protein \\
\hline$R v 3136$ & $M b 3160$ & PPE51 & 9.6 & PPE family protein \\
\hline$R v 3137$ & $M b 3161$ & & 3.6 & $\mathrm{Mg}^{2+}$-dependent phosphatase \\
\hline$R v 3312 A$ & $M b 3341 c$ & & 5.9 & Secreted antigen \\
\hline$R v 3407$ & $M b 3441$ & $v a p B-44$ & 17.1 & $\mathrm{PhD}$ antitoxin \\
\hline$R v 3408$ & $M b 3442$ & vapC-44 & 4.8 & PIN domain \\
\hline$R v 3409 c$ & $M b 3443 c$ & choD & 3.8 & Putative cholesterol oxidase precursor \\
\hline$R v 3420 c$ & $M b 3454 c$ & $\operatorname{rimI}$ & 3.1 & Ribosomal protein acetyltransferase \\
\hline$R v 3479$ & $M b 3506$ & & 3.5 & Transmembrane protein \\
\hline Rv3581c & $M b 3612 c$ & $i s p F$ & 3.7 & Erythritol cyclodiphosphate synthase \\
\hline$R v 3679$ & $M b 3704$ & & 12.4 & Putative anion transporter \\
\hline$R v 3686 c$ & $M b 3711 c$ & & 3.4 & Conserved hypothetical protein \\
\hline$R v 3750 c$ & $M b 3376 c$ & & 6.6 & Putative excisionase \\
\hline$R v 3823 c$ & $M b 3853 c$ & $m m p L 8$ & 4.1 & Sulfolipid biosynthesis \\
\hline$R v 3824 c$ & $M b 3854 c$ & papA1 & 4.8 & Sulfolipid biosynthesis \\
\hline$R v 3825 c$ & $M b 3855 c$ & $p k s 2$ & 4.1 & Sulfolipid biosynthesis \\
\hline$R v 3848$ & $M b 3878$ & & 4.5 & Transmembrane protein \\
\hline
\end{tabular}

The level of expression of virS was 10-fold higher in $M$. bovis compared with $M$. tuberculosis (Table 1). In $M$. tuberculosis, VirS has been shown to regulate expression of the genes $R v 3083-R v 3089$, the products of which could be involved in the modification of fatty acids in the cell envelope (Singh et al., 2003). However, no differential 
expression of these latter genes between $M$. tuberculosis and M. bovis was observed.

Clearly, a full description of the regulatory networks controlled by the transcription factors named above is required if their role in the phenotypic discrimination of human and bovine bacilli is to be defined. The application of genome-wide location studies, such as chromatinimmunoprecipitation assays, will aid in the identification of these gene networks (Rodrigue et al., 2007).

\section{PE and PPE family}

The PE and PPE proteins are two large protein families with $>160$ members in $M$. tuberculosis and M. bovis. Approximately $60 \%$ of the PE and PPE proteins differ across the two strains, a feature clearly at odds with the high sequence identity across the majority of encoded proteins in human and bovine bacilli (Cole et al., 1998; Garnier et al., 2003). While the precise function of the PE and PPE proteins remains to be defined, members have been implicated in virulence and antigenic variation. As well as variation at the nucleotide level, it is therefore interesting that the genes encoding PPE33, PE35, PPE51 and PPE55 showed variation in expression between $M$. tuberculosis $\mathrm{H} 37 \mathrm{Rv}$ and M. bovis AF2122 (Tables 1 and 2). The higher expression of the gene encoding PPE33, $R v 1809$, in $M$. tuberculosis may be due to the M. bovis orthologue being frameshifted $(M b 1838 / M b 1839)$, thus disrupting its correct regulation. Rv3136, which encodes PPE51, has been shown to be one of 22 genes that are consistently up-regulated in M. tuberculosis H37Rv compared to the attenuated derivative H37Ra (Mostowy et al., 2004), a result that parallels its decreased expression in $M$. bovis. The differential expression of PPE genes between human and bovine bacilli points to subtle variation in the control of these genes among strains, the biological implications of which remain to be defined.

\section{TAs}

TA modules were originally described as plasmid maintenance systems that trigger post-segregational killing of plasmid-free cells (Gerdes et al., 2005). The TA pair is transcriptionally coupled, with the antitoxin typically acting both to repress transcription of the locus and inhibiting the action of the toxin. In response to various stresses, toxin release can lead to growth arrest and antibiotic tolerance (Correia et al., 2006). At least 60 TA genes have been discovered in the genome of $M$. tuberculosis, a very high number compared to most other sequenced bacteria (Arcus et al., 2005; Pandey \& Gerdes, 2005).

TA pairs showed variation in expression between $M$. tuberculosis and M. bovis. Rv3407-Rv3408 were up-regulated in M. tuberculosis $\mathrm{H} 37 \mathrm{Rv}$ (Table 2) and encode a TA pair (belonging to the vapBC family) designated vapBC-44 by Pandey \& Gerdes (2005); Rv3407 encodes the antitoxin, and $R v 3408$ the PilT amino terminus (PIN) domain toxin. M. tuberculosis also showed up-regulation of $R v 1397 c$ $R v 1398 c$, another TA pair designated vapBC-20 (D. P. Pandey \& K. Gerdes, unpublished). Comparative proteome analysis of BCG and M. tuberculosis showed that Rv3407 is present at lower levels in BCG than $M$. tuberculosis (Jungblut et al., 1999). Inactivation of four of the five $M$. tuberculosis rpf genes, encoding glycolytic hydrolases implicated in resuscitation of dormant bacilli, led to upregulation of $R v 3407 / 3408$; however, inactivation of the one $r p f$ gene which is different between $M$. bovis and $M$. tuberculosis, rpfA, had no effect on Rv3407/3408 expression (Downing et al., 2004). Interestingly, an RD1 knockout of M. tuberculosis showed a 10-fold up-regulation of Rv3407 and Rv3408 (Mostowy et al., 2004). However, BCG is deleted for RD1, yet shows low expression of its Rv3407/ Rv3408 orthologues (Jungblut et al., 1999), again pointing to defective regulation of the vapBC-44 locus in $M$. bovis strains.

In M. bovis, Mb0066, encoding a PIN domain protein, was expressed at higher levels than in M. tuberculosis; however, no upstream antitoxin had been annotated (Garnier et al., 2003). Using exhaustive searches for TA loci, Pandey \& Gerdes (2005) identified a putative CDS upstream of $M b 0066 / R v 0065$ that they designated $v a p B-1$ and that encodes the antitoxin for $M b 0066 / R v 0065$ (vapC-1). In keeping with $M$. bovis genome nomenclature, we designated this upstream CDS Mb0066A. Using qRT-PCR analyses we confirmed both the transcription of the Mb0066A/vapB-1 CDS in M. bovis and M. tuberculosis and the increased expression of $M b 0066 A$ in $M$. bovis compared to M. tuberculosis (Fig. 1).

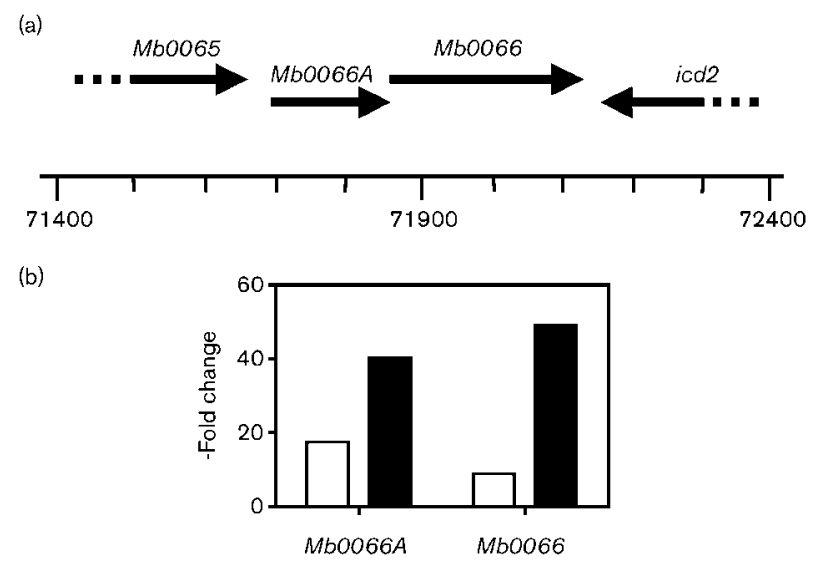

Fig. 1. Up-regulation of a TA pair in $M$. bovis compared with $M$. tuberculosis. (a) Map of the chromosomal location of Mb0066A/ $M b 0066$ in $M$. bovis. (b) -Fold increase in expression of Mb0066A/Mb0066 in M. bovis (black bars) compared with $M$. tuberculosis (white bars) during steady-state growth as measured by qRT-PCR. Data are the means of two independent experiments. 
The biological importance of TA pair differential expression is unclear. However, evidence from E. coli has shown that some TAs play roles in the generation of drug-resistant 'persister' populations (Correia et al., 2006; Keren et al., 2004). Given the increased emergence of drug-resistant populations of $M$. tuberculosis, exploration of the function of TA proteins is a high priority, and further studies of the pairs that show differential expression between $M$. tuberculosis and $M$. bovis may offer an ideal starting point to elucidate function.

\section{Verification by qRT-PCR}

To confirm gene expression differences predicted by array analysis, real-time qRT-PCR was performed. All of the 92 genes showing differential regulation between $M$. tuberculosis and M. bovis could not be analysed due to cost implications, so a subset of nine was selected that included genes involved in transcriptional regulation $(M b 2654 c$, virS, whiB4), lipid metabolism (Rv1184c, Mb0222), and a TA pair (Rv3407). Fig. 2 compares the -fold changes in expression measured by microarray and qRT-PCR for these nine genes. The results showed that both methods display broad agreement in their measurements of expression for each gene, confirming that experimental procedures and data handling had not introduced any significant bias to the dataset.

\section{Acid-shock response of $M$. tuberculosis and $M$. bovis}

Our chemostat experiments defined a core gene set that showed differential expression between M. tuberculosis and $M$. bovis during steady-state growth. However, we also wished to determine if the response to a perturbation of steady-state was significantly different between the strains. We chose acid shock as this perturbation, a biologically relevant stress experienced by mycobacteria during infection. Cultures were grown to steady-state, then the $\mathrm{pH}$ dropped to 5.5 and gene expression was monitored over a $24 \mathrm{~h}$ period at 5, 15, 30 and $60 \mathrm{~min}$ and $24 \mathrm{~h}$ after acid shock. We identified $150 \mathrm{M}$. tuberculosis genes and $66 \mathrm{M}$. bovis genes that showed a minimum of a threefold change in expression post-acid-shock compared with the steadystate, zero time point (see supplementary Tables S2 and S3, available with the online version of this paper, for a full listing of all M. tuberculosis and M. bovis genes that were responsive to acid shock).

While M. tuberculosis showed repression of 44 genes in response to acid shock across all time points (Table S2), $M$. bovis repressed only six genes (Table S3), with just Rv3269/ $M b 3298$, encoding a protein of unknown function, common to both species. In terms of gene induction, 106 $M$. tuberculosis genes showed increased expression, compared to $60 \mathrm{M}$. bovis genes, with 15 genes in common (Tables S2 and S3). Temporal changes in gene expression were evident in M. tuberculosis and M. bovis, with some

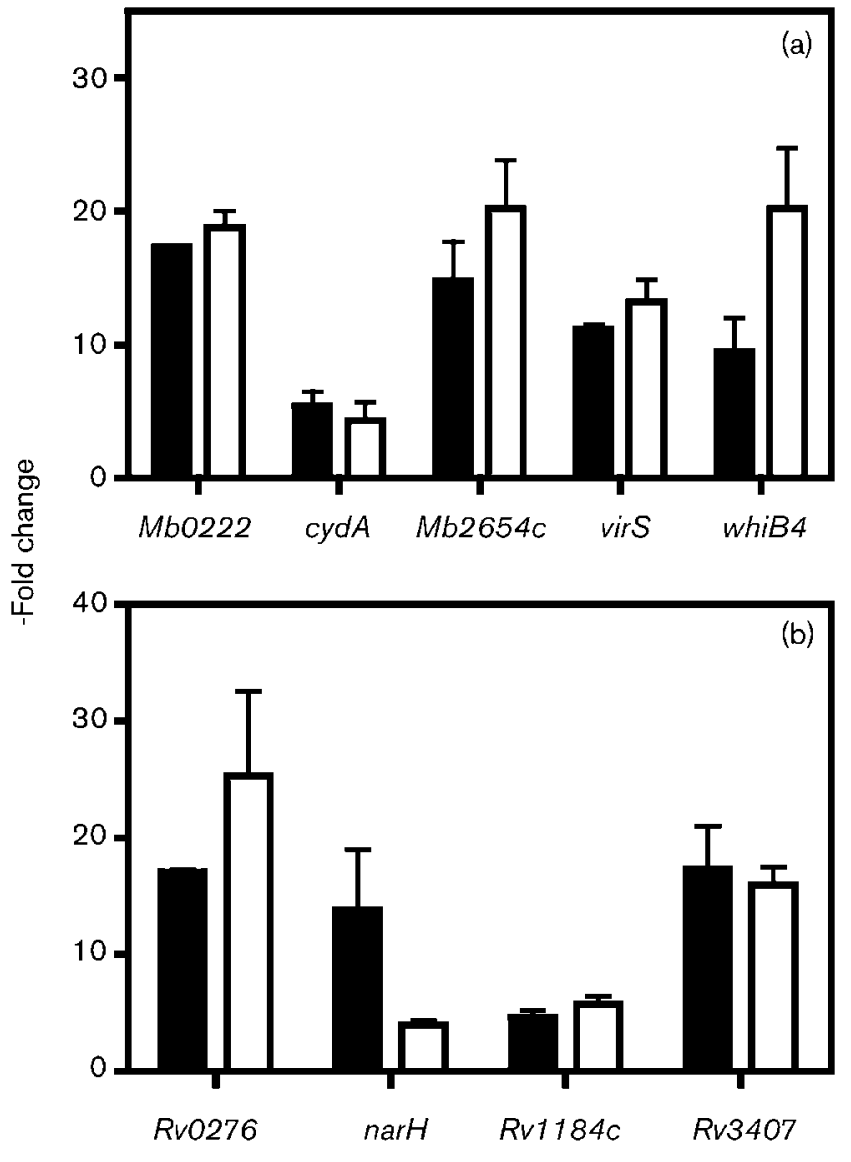

Fig. 2. Confirmation of microarray results using qRT-PCR. Selected genes that show higher levels of expression in M. bovis compared with M. tuberculosis (a), or higher levels of expression in M. tuberculosis compared with $M$. bovis (b) in steady-state samples, as measured by microarray (black bars) and qRT-PCR (white bars). Data are the means of two independent experiments.

genes showing 'early' induction (5-60 min), while others were only induced at the 'late' $(24 \mathrm{~h})$ time point. At the global level it was apparent that $M$. tuberculosis and $M$. bovis showed significant differences in their response to acid stress. Below we highlight the commonality and differences in this temporal response.

\section{Common acid-shock response}

Two genes encoding putative methyltransferases, $R v 1403 c /$ $M b 1438 c$ and $R v 1405 c / M b 1440 c$, were induced early after acid shock in both M. tuberculosis and M. bovis (Table 3). Rv1404/Mb1439 lies between the genes and encodes a MarR family transcriptional repressor that regulates expression of $R v 1405 c$ and $R v 1403 c$ (P. Golby, unpublished). Previous work has shown that $R v 1405 c$ was strongly up-regulated in macrophages (Schnappinger et al., 2003), while transposon site hybridization studies identified $R v 1405 c$ as one of 194 genes predicted to be essential for survival of $M$. tuberculosis in vivo (Sassetti \& Rubin, 2003). The target(s) 
Table 3. M. tuberculosis and $M$. bovis genes up-regulated in response to acid-shock

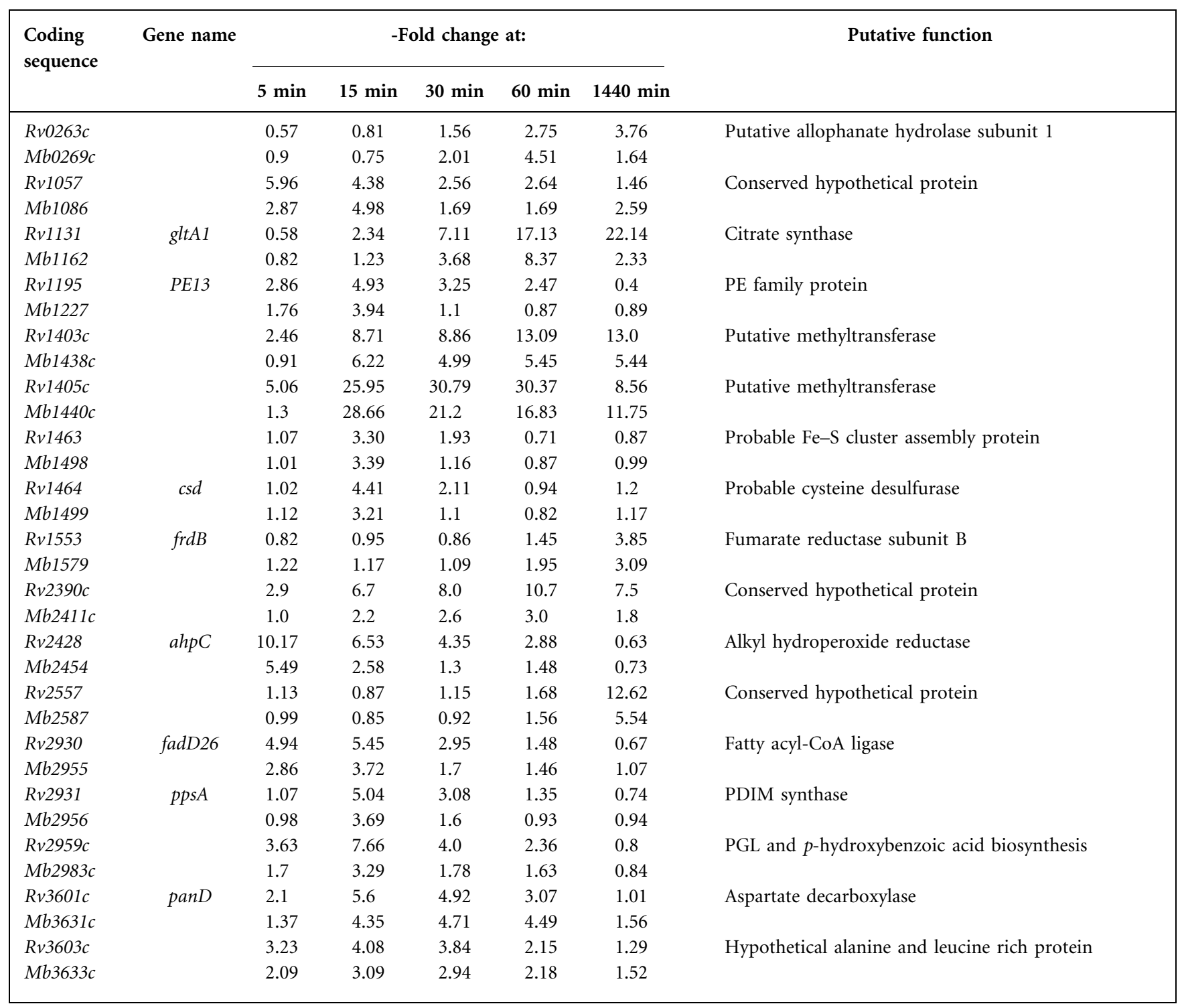

of Rv1405c and Rv1403c are unknown. Methyltransferasemediated modification of unsaturated fatty acids to produce cyclopropane fatty acids is a known acid resistance mechanism in E. coli (Grogan \& Cronan, 1997). The gene encoding the cyclopropane fatty-acyl synthase, $c f a$, is also up-regulated in response to low $\mathrm{pH}$ in E. coli (Maurer et al., 2005). However, Rv1403c and Rv1405c show low similarity to cyclopropane fatty-acyl synthases, suggesting this is not their function. Identification of the methylated target will help to shed light on the function of Rv1403c/Mb1438c and $\mathrm{Rv} 1405 \mathrm{c} / \mathrm{Mb} 1440 \mathrm{c}$ both in virulence and in response to stress.

Genes involved in PDIM synthesis were up-regulated in both M. tuberculosis and M. bovis, with fadD26, ppsA and $R v 2959 c$ showing maximal induction after 5-10 min, with expression then decreasing over the $24 \mathrm{~h}$ period (Table 3 ). $p p s B$ and $p p s E$ also showed up-regulation over the same time frame in M. tuberculosis (Table 4). It has previously been shown that mutants lacking PDIM have increased permeability (Camacho et al., 2001), suggesting that the early up-regulation of PDIM biosynthesis may be a general stress response that attempts to remodel the cell wall, decreasing permeability to damaging agents. This is similar to the suggested role for increased levels of cyclopropane fatty acids in membrane lipids of acid-tolerant E. coli, with conversion of unsaturated to cyclopropane fatty acids leading to a decrease in proton permeability (Grogan \& Cronan, 1997).

$R v 0263 c / M b 0269 c$ was up-regulated 30-60 min after acidshock (Table 3 ) and its predicted protein sequence shows similarity to allophanate hydrolase subunit 2 which hydrolyses urea carboxylate to carbon dioxide and ammonia. Up-regulation would lead to increased ammonia production, hence acting to buffer the cytoplasmic $\mathrm{pH}$ 
Table 4. M. tuberculosis and M. bovis genes that showed differential expression between the strains after acid shock

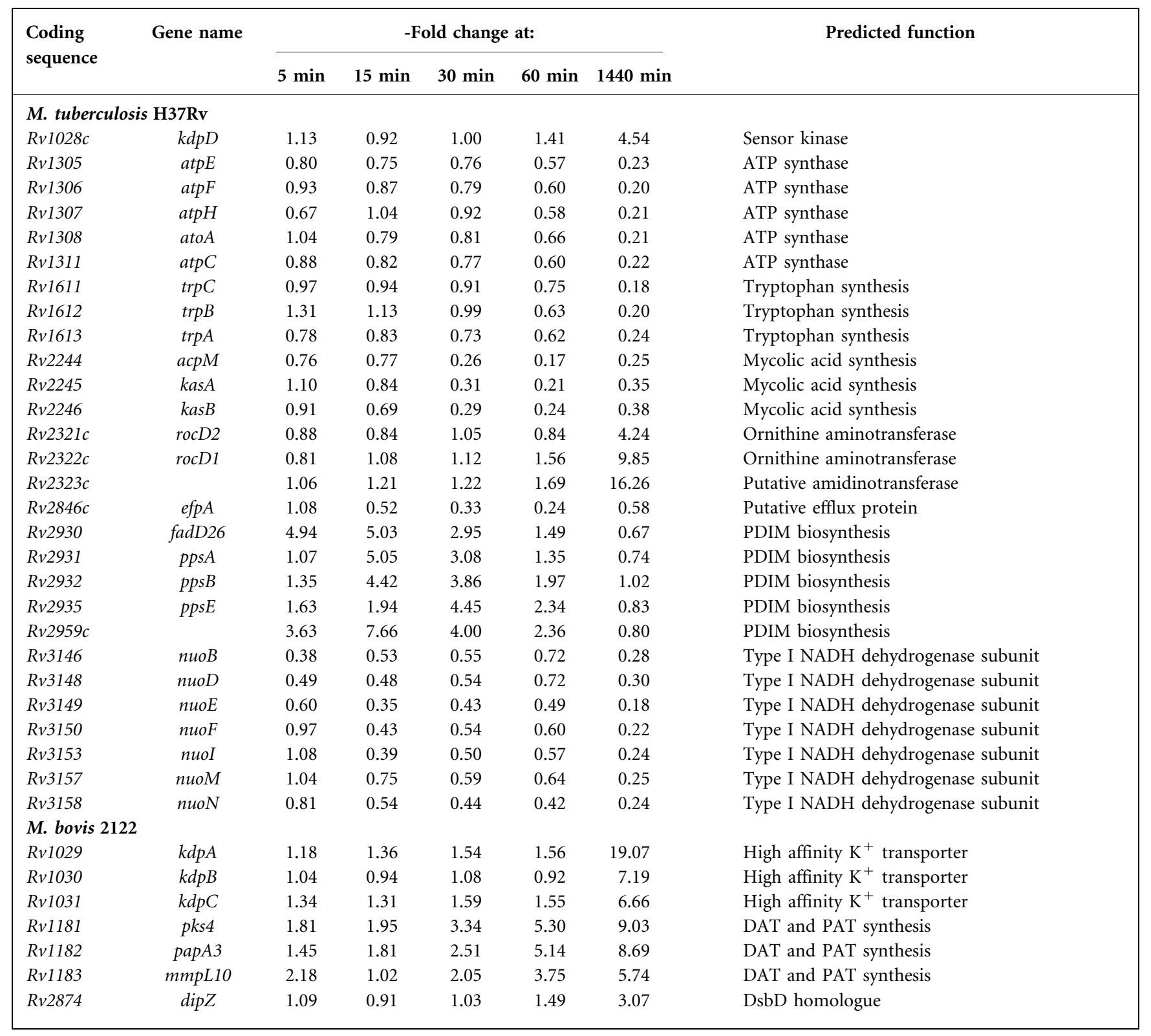

during acid stress. Tubercle bacilli also contain the 'classic' bacterial nickel-containing UreABC enzyme, but the genes encoding this complex were not up-regulated. While pathogens such Helicobacter pylori are known to produce high levels of urease as a means of protection against host acidic environments (Weeks et al., 2000), this is the first report of up-regulation of urease genes in tubercle bacilli in response to acid stress.

\section{Differential acid-shock response}

Among the 44 genes repressed in M. tuberculosis in response to acid-shock were two clusters of genes involved in energy transduction (Table 4). Five atp genes encoding components of the membrane-bound proton-translocating ATP synthase were down-regulated in M. tuberculosis. As this system serves to import protons, and hence acidify the cytoplasm, its repression under acid stress would aid in maintaining cytoplasmic $\mathrm{pH}$ near neutrality. However, seven nuo genes encoding subunits of the type I NADH dehydrogenase, which serves to export protons, were also down-regulated. As proton export would help to maintain cytoplasmic $\mathrm{pH}$ under acid-stress, the repression of the nuo operon is surprising. A previous analysis of the $M$. tuberculosis acid-shock response also noted down-regulation of genes encoding type I NADH dehydrogenase subunits nuoA and nuoG (Fisher et al., 2002). The repression of both proton influx and efflux systems in $M$. tuberculosis, and their differential expression between $M$. tuberculosis and M. bovis, suggests a complex dynamic in the control of these systems in response to acid stress. This does not of course mean that constitutive $\mathrm{pH}$ homeostasis 
systems that direct proton efflux, such as cytochrome respiratory chains (Booth, 1985), are not important.

The $k d p A B C$ operon encodes a high affinity $\mathrm{K}^{+}$uptake system that is regulated by turgor pressure in E. coli (Malli \& Epstein, 1998). In M. bovis 2122, this operon was found to be induced at the $24 \mathrm{~h}$ time point, while in $M$. tuberculosis $\mathrm{H} 37 \mathrm{Rv}$ only $k d p D$, encoding the sensor kinase that controls $k d p A B C$ expression, was up-regulated after $24 \mathrm{~h}$ (Table 4). Under conditions of cytoplasm acidification, protons need to be removed from the cytoplasm; however, to maintain electrochemical neutrality, positively charged ions must be introduced. Hence, induction of $\mathrm{K}^{+}$ uptake systems allows the cell to maintain electrochemical gradients (Booth, 1985). As proton extrusion would need to occur quickly after acidification of the cytoplasm begins, it is therefore puzzling that $k d p A B C$ was induced only at the late time point in M. bovis. For example, for osmotic stress in Salmonella, it has been shown that up-regulation of $k d p A B C$ occurs less than $10 \mathrm{~min}$ after exposure to the stress (Balaji et al., 2005). This suggests that the upregulation of $k d p A B C$ in $M$. bovis seen here is either not a direct response to acid stress, or that the temporal response is markedly different in $M$. bovis compared to other bacteria. Monitoring the expression of $k d p A B C$ in $M$. bovis and M. tuberculosis in response to osmotic stresses will help to unravel the role of $\mathrm{K}^{+}$import for homeostasis in the tubercle bacilli.

Differential expression of amino acid biosynthesis genes in response to acid shock was seen. M. tuberculosis repressed the tryptophan biosynthetic genes $\operatorname{trpCBA} 30 \mathrm{~min}$ after the $\mathrm{pH}$ drop, but induced the expression of the rocD2-rocD1$R v 2323 c$ locus over the same time period, reaching maximal expression by $24 \mathrm{~h}$ (Table 4). This latter frameshifted locus encodes an ornithine aminotransferase $(\operatorname{RocD})$, and a putative amidinotransferase (Rv2323c), enzymes that are involved in the urea cycle and hence lead to ammonia production. As with up-regulation of ureases, increased production of ammonia will serve to increase cytoplasmic $\mathrm{pH}$ in the face of proton efflux.

While the pks4-papA3-mmpL10 locus involved in DAT and PAT synthesis was expressed at lower levels in M. bovis than M. tuberculosis under steady-state conditions (Table 1; see above), this region was up-regulated in $M$. bovis after acid shock, reaching maximum expression after $24 \mathrm{~h}$ (Table 4). In M. tuberculosis, acpM-kasA-kasB, involved in mycolic acid biosynthesis, were down-regulated across all time points, as was efpA; repression of these genes has been shown to be a signature for agents that effect fatty acid synthesis (Boshoff et al., 2004). As with up-regulation of PDIM synthetic loci that was seen in both strains in response to acid shock, altered expression of genes involved in cell wall synthesis suggests remodelling of cell wall architecture in response to stress. Indeed, the hydrophobic cell wall acts as a major protective barrier for the bacillus, so maintaining its integrity is clearly of major importance for the cell.
The dipZ gene, one of the SigK regulon genes whose expression is higher in M. bovis than M. tuberculosis, was up-regulated threefold after acid shock only in M. bovis at the $24 \mathrm{~h}$ time point. As this gene is already highly expressed in M. bovis (Table 1), its up-regulation is intriguing. None of the other SigK regulon genes was expressed at higher levels after acid shock, indicating SigK-independent regulation. DipZ is a homologue of DsbD in E. coli, which functions to transfer reducing power from the cytoplasm to the periplasm and plays key roles in the cytochrome $c$ assembly pathway and correct disulfide-bond formation in proteins (Kadokura et al., 2003). The crystal structure of the C-terminal domain of DipZ revealed a dimeric structure with an expected thioredoxin-like fold, but also an unexpected fold with similarity to carbohydrate-binding modules, suggesting a role in carbohydrate processing (Goldstone et al., 2005). As cytochrome respiratory chains are key mediators of $\mathrm{pH}$ homeostasis through proton efflux (Booth, 1985), up-regulation of $\operatorname{dip} Z$ may reflect an increased requirement for cytochrome biogenesis. However, the unique structural features of DipZ suggest it could play a novel role that remains to be elucidated.

\section{Conclusions}

The M. tuberculosis complex can be viewed as a set of ecotypes with distinct host preferences (Smith et al., 2006), the basis of which is encoded in the pathogen's genomes. Comparative analyses of the M. tuberculosis and M. bovis genomes has identified a set of genetic differences between these strains, some of which have been linked to known in vitro phenotypic differences (Keating et al., 2005; SaidSalim et al., 2006; Stermann et al., 2004). However, comparative genomics cannot provide a full picture of the impact of genetic change on phenotype. To accelerate our identification of candidate genes that contribute to the phenotypes of $M$. tuberculosis and M. bovis, we therefore sought to identify key gene expression differences between the strains.

In defining core gene expression differences it is essential that growth conditions are identical between cultures. We chose continuous culture since it allows environmental conditions and bacterial growth rates to be tightly and reproducibly controlled, reducing variation between biological replicates. A seminal example of the need to control growth rate in transcriptome experiments has been provided by a global analysis of central carbon metabolism in E. coli using gene expression, protein and metabolome data (Ishii et al., 2007). Using glucose-limited chemostat cultures of E. coli, it was found that the effect of variation in growth rate on the transcriptome and proteome was larger than the effects of most gene disruptions in carbon metabolism. We are therefore confident that our profile of steady-state gene expression in M. tuberculosis and M. bovis identifies key gene expression differences between the strains, rather than being simple growth rate or media effects. 
In a recent publication, Rehren et al. (2007) described the transcriptome of $M$. tuberculosis $\mathrm{H} 37 \mathrm{Rv}$ and $M$. bovis Ravanel grown in batch culture, identifying 278 genes with differential expression. Comparing their results with our data, 45 genes appear in both datasets, with 325 gene differences. Whether these differences are due to variation between M. bovis Ravanel and M. bovis 2122, or are down to technical differences between the experiments, is difficult to assess. For example, while we grew both $M$. tuberculosis $\mathrm{H} 37 \mathrm{Rv}$ and M. bovis 2122 on Tween 80 as sole carbon source, Rehren and colleagues grew H37Rv in Middlebrook 7H9 medium with glycerol, while the Ravanel strain was grown in $7 \mathrm{H} 9$ medium with pyruvate; hence, some of their gene expression differences may be due to different carbon source utilization. The two studies also used different microarrays and data handling procedures, a further source of variation. Hence, the 'minimal' set of differentially expressed genes between $M$. tuberculosis and $M$. bovis remains to be defined.

Prior to our work, Fisher et al. (2002) studied the effect of acid on the transcriptome of $M$. tuberculosis H37Rv, but in batch culture. Overlap between the genes differentially expressed in response to acid stress identified here and in their work is apparent, with Rv1130, gltA1, PE13, acpM, $k a s A B, a h p C D$ and efpA identified in both analyses. However, some key differences in the data were also apparent, such as the induction of a putative polyketide synthase operon $(R v 3083-R v 3089)$ in their work which we did not see in M. tuberculosis or M. bovis. Conversely, the strong induction of the putative methyltransferase-encoding genes $R v 1405 c$ and $R v 1403 c$ seen by us in both $M$. tuberculosis and M. bovis was not reported by Fisher and colleagues, although they did see a slight induction of $R v 1404$, which encodes the putative regulator of $R v 1405 c$ and $R v 1403 c$. It is difficult to determine whether the variation in expression profile between the two studies is due to choice of strain, growth condition, experimental procedures or data handling.

In summary, we have defined key gene expression differences between the sequenced $M$. tuberculosis $\mathrm{H} 37 \mathrm{Rv}$ and M. bovis 2122 strains, and have identified candidate genes that may play pivotal roles in the pathogenic process. The focus now is to explore the role of this differential gene expression in the distinct host preference of the human and bovine tubercle bacilli.

\section{ACKNOWLEDGEMENTS}

This work was funded by the UK Department for Environment, Food and Rural Affairs (Defra), the Department of Health, and the Health Protection Agency. The authors would like to thank Paul Wheeler and Lisa Keating (VLA) for their help in the development of the chemostat growth medium for M. bovis, and for useful discussions on the microarray data. We would like to acknowledge Jason Sawyer (VLA) for developing a protocol for qRT-PCR, to thank Lucy Brooks and Adam Whitney (Bacterial Microarray Group, St Georges) for help with depositing data in B $\mu \mathrm{G} @ S b a s e$ and ArrayExpress, and acknowledge Colorado State University for the provision of M. tuberculosis
H37Rv genomic DNA produced under NIH contract HHSN266200400091C/ADB NO1-A1-40091 'Tuberculosis Vaccine Testing and Research Materials Contract'. The views expressed in the publication are those of the authors and not necessarily those of the Department of Health and Health Protection Agency.

\section{REFERENCES}

Alam, M. S., Garg, S. K. \& Agrawal, P. (2007). Molecular function of WhiB4/Rv3681c of Mycobacterium tuberculosis H37Rv: a [4Fe-4S] cluster co-ordinating protein disulphide reductase. Mol Microbiol 63, 1414-1431.

Arcus, V. L., Rainey, P. B. \& Turner, S. J. (2005). The PIN-domain toxin-antitoxin array in mycobacteria. Trends Microbiol 13, 360-365.

Bacon, J., James, B. W., Wernisch, L., Williams, A., Morley, K. A., Hatch, G. J., Mangan, J. A., Hinds, J., Stoker, N. G. \& other authors (2004). The influence of reduced oxygen availability on pathogenicity and gene expression in Mycobacterium tuberculosis. Tuberculosis (Edinb) 84, 205-217.

Balaji, B., O'Connor, K., Lucas, J. R., Anderson, J. M. \& Csonka, L. N. (2005). Timing of induction of osmotically controlled genes in Salmonella enterica serovar Typhimurium, determined with quantitative real-time reverse transcription-PCR. Appl Environ Microbiol 71, 8273-8283.

Bhatt, K., Gurcha, S. S., Bhatt, A., Besra, G. S. \& Jacobs, W. R., Jr (2007). Two polyketide-synthase-associated acyltransferases are required for sulfolipid biosynthesis in Mycobacterium tuberculosis. Microbiology 153, 513-520.

Booth, I. R. (1985). Regulation of cytoplasmic $\mathrm{pH}$ in bacteria. Microbiol Rev 49, 359-378.

Boshoff, H. I., Myers, T. G., Copp, B. R., McNeil, M. R., Wilson, M. A. \& Barry, C. E., III (2004). The transcriptional responses of Mycobacterium tuberculosis to inhibitors of metabolism: novel insights into drug mechanisms of action. J Biol Chem 279, 40174-40184.

Camacho, L. R., Constant, P., Raynaud, C., Laneelle, M. A., Triccas, J. A., Gicquel, B., Daffe, M. \& Guilhot, C. (2001). Analysis of the phthiocerol dimycocerosate locus of Mycobacterium tuberculosis. Evidence that this lipid is involved in the cell wall permeability barrier. J Biol Chem 276, 19845-19854.

Chan, J., Silver, R. F., Kampmann, B. \& Wallis, R. S. (2005). Intracellular models of Mycobacterium tuberculosis infection. In Tuberculosis and the Tubercle Bacillus, pp. 437-461. Edited by S. T. Cole, K. D. Eisenach, D. N. McMurray \& W. R. Jacobs Jr. Washington, DC: American Society for Microbiology.

Charlet, D., Mostowy, S., Alexander, D., Sit, L., Wiker, H. G. \& Behr, M. A. (2005). Reduced expression of antigenic proteins MPB70 and MPB83 in Mycobacterium bovis BCG strains due to a start codon mutation in sigK. Mol Microbiol 56, 1302-1313.

Cole, S. T., Brosch, R., Parkhill, J., Garnier, T., Churcher, C., Harris, D., Gordon, S. V., Eiglmeier, K., Gas, S. \& other authors (1998). Deciphering the biology of Mycobacterium tuberculosis from the complete genome sequence. Nature 393, 537-544.

Cole, S. T., Eiglmeier, K., Parkhill, J., James, K. D., Thomson, N. R., Wheeler, P. R., Honoré, N., Garnier, T., Churcher, C. \& other authors (2001). Massive gene decay in the leprosy bacillus. Nature 409, 1007-1011.

Constant, P., Perez, E., Malaga, W., Laneelle, M. A., Saurel, O., Daffe, M. \& Guilhot, C. (2002). Role of the pks15/1 gene in the biosynthesis of phenolglycolipids in the $M$. tuberculosis complex: evidence that all strains synthesize glycosylated $\mathrm{P}^{-}$-hydroxybenzoic methyl esters and that strains devoid of phenolglycolipids harbour a frameshift mutation in the pks15/ 1 gene. J Biol Chem 277, 38148-38158. 
Converse, S. E., Mougous, J. D., Leavell, M. D., Leary, J. A., Bertozzi, C. R. \& Cox, J. S. (2003). MmpL8 is required for sulfolipid-1 biosynthesis and Mycobacterium tuberculosis virulence. Proc Natl Acad Sci U S A 100, 6121-6126.

Correia, F. F., D'Onofrio, A., Rejtar, T., Li, L., Karger, B. L., Makarova, K., Koonin, E. V. \& Lewis, K. (2006). Kinase activity of overexpressed HipA is required for growth arrest and multidrug tolerance in Escherichia coli. J Bacteriol 188, 8360-8367.

Davis, N. K. \& Chater, K. F. (1992). The Streptomyces coelicolor whiB gene encodes a small transcription factor-like protein dispensable for growth but essential for sporulation. Mol Gen Genet 232, 351-358.

Downing, K. J., Betts, J. C., Young, D. I., McAdam, R. A., Kelly, F., Young, M. \& Mizrahi, V. (2004). Global expression profiling of strains harbouring null mutations reveals that the five $r p f$-like genes of Mycobacterium tuberculosis show functional redundancy. Tuberculosis (Edinb) 84, 167-179.

Dubey, V. S., Sirakova, T. D. \& Kolattukudy, P. E. (2002). Disruption of $m s l 3$ abolishes the synthesis of mycolipanoic and mycolipenic acids required for polyacyltrehalose synthesis in Mycobacterium tuberculosis H37Rv and causes cell aggregation. Mol Microbiol 45, 1451-1459.

Dubos, R. J. \& Davis, B. D. (1946). Factors affecting the growth of tubercle bacilli in liquid media. J Exp Med 83, 409-423.

Fisher, M. A., Plikaytis, B. B. \& Shinnick, T. M. (2002). Microarray analysis of the Mycobacterium tuberculosis transcriptional response to the acidic conditions found in phagosomes. J Bacteriol 184, 4025-4032.

Garnier, T., Eiglmeier, K., Camus, J. C., Medina, N., Mansoor, H., Pryor, M., Duthoy, S., Grondin, S., Lacroix, C. \& other authors (2003). The complete genome sequence of Mycobacterium bovis. Proc Natl Acad Sci U S A 100, 7877-7882.

Geiman, D. E., Raghunand, T. R., Agarwal, N. \& Bishai, W. R. (2006). Differential gene expression in response to exposure to antimycobacterial agents and other stress conditions among seven Mycobacterium tuberculosis whiB-like genes. Antimicrob Agents Chemother 50, 2836-2841.

Gerdes, K., Christensen, S. K. \& Lobner-Olesen, A. (2005). Prokaryotic toxin-antitoxin stress response loci. Nat Rev Microbiol 3, 371-382.

Goldstone, D., Baker, E. N. \& Metcalf, P. (2005). Crystallization and preliminary diffraction studies of the C-terminal domain of the DipZ homologue from Mycobacterium tuberculosis. Acta Crystallograph Sect F Struct Biol Cryst Commun 61, 243-245.

Gonzalo Asensio, J., Maia, C., Ferrer, N. L., Barilone, N., Laval, F., Soto, C. Y., Winter, N., Daffé, M., Gicquel, B. \& other authors (2006). The virulence-associated two-component PhoP-PhoR system controls the biosynthesis of polyketide-derived lipids in Mycobacterium tuberculosis. J Biol Chem 281, 1313-1316.

Grogan, D. W. \& Cronan, J. E., Jr (1997). Cyclopropane ring formation in membrane lipids of bacteria. Microbiol Mol Biol Rev 61, 429-441.

Hewinson, R. G., Michell, S. L., Russell, W. P., McAdam, R. A. \& Jacobs, W. R., Jr (1996). Molecular characterization of MPT83: a seroreactive antigen of Mycobacterium tuberculosis with homology to MPT70. Scand J Immunol 43, 490-499.

Hoskisson, P. A. \& Hobbs, G. (2005). Continuous culture - making a comeback? Microbiology 151, 3153-3159.

Ishii, N., Nakahigashi, K., Baba, T., Robert, M., Soga, T., Kanai, A., Hirasawa, T., Naba, M., Hirai, K. \& other authors (2007). Multiple high-throughput analyses monitor the response of $E$. coli to perturbations. Science 316, 593-597.

Jain, S. K., Paul-Satyaseela, M., Lamichhane, G., Kim, K. S. \& Bishai, W. R. (2006). Mycobacterium tuberculosis invasion and traversal across an in vitro human blood-brain barrier as a pathogenic mechanism for central nervous system tuberculosis. J Infect Dis 193, 1287-1295.

Jakimowicz, P., Cheesman, M. R., Bishai, W. R., Chater, K. F., Thomson, A. J. \& Buttner, M. J. (2005). Evidence that the Streptomyces developmental protein WhiD, a member of the WhiB family, binds a [4Fe-4S] cluster. J Biol Chem 280, 8309-8315.

James, B. W., Williams, A. \& Marsh, P. D. (2000). The physiology and pathogenicity of Mycobacterium tuberculosis grown under controlled conditions in a defined medium. J Appl Microbiol 88, 669-677.

Jungblut, P. R., Schaible, U. E., Mollenkopf, H. J., Zimny-Arndt, U., Raupach, B., Mattow, J., Halada, P., Lamer, S., Hagens, K., Kaufmann, S. H. \& other authors (1999). Comparative proteome analysis of Mycobacterium tuberculosis and Mycobacterium bovis BCG strains: towards functional genomics of microbial pathogens. Mol Microbiol 33, 1103-1117.

Kadokura, H., Katzen, F. \& Beckwith, J. (2003). Protein disulfide bond formation in prokaryotes. Annu Rev Biochem 72, 111-135.

Keating, L. A., Wheeler, P. R., Mansoor, H., Inwald, J. K., Dale, J., Hewinson, R. G. \& Gordon, S. V. (2005). The pyruvate requirement of some members of the Mycobacterium tuberculosis complex is due to an inactive pyruvate kinase: implications for in vivo growth. Mol Microbiol 56, 163-174.

Keren, I., Shah, D., Spoering, A., Kaldalu, N. \& Lewis, K. (2004). Specialized persister cells and the mechanism of multidrug tolerance in Escherichia coli. J Bacteriol 186, 8172-8180.

Malli, R. \& Epstein, W. (1998). Expression of the Kdp ATPase is consistent with regulation by turgor pressure. J Bacteriol 180, 5102-5108.

Maurer, L. M., Yohannes, E., Bondurant, S. S., Radmacher, M. \& Slonczewski, J. L. (2005). pH regulates genes for flagellar motility, catabolism, and oxidative stress in Escherichia coli K-12. J Bacteriol 187, 304-319.

Mostowy, S., Cleto, C., Sherman, D. R. \& Behr, M. A. (2004). The Mycobacterium tuberculosis complex transcriptome of attenuation. Tuberculosis (Edinb) 84, 197-204.

Mostowy, S., Inwald, J., Gordon, S., Martin, C., Warren, R., Kremer, K., Cousins, D. \& Behr, M. A. (2005). Revisiting the evolution of Mycobacterium bovis. J Bacteriol 187, 6386-6395.

Pandey, D. P. \& Gerdes, K. (2005). Toxin-antitoxin loci are highly abundant in free-living but lost from host-associated prokaryotes. Nucleic Acids Res 33, 966-976.

Rehren, G., Walters, S., Fontan, P., Smith, I. \& Zarraga, A. M. (2007). Differential gene expression between Mycobacterium bovis and Mycobacterium tuberculosis. Tuberculosis (Edinb) 87, 347-359.

Rodrigue, S., Brodeur, J., Jacques, P. E., Gervais, A. L., Brzezinski, R. \& Gaudreau, L. (2007). Identification of mycobacterial sigma factor binding sites by chromatin immunoprecipitation assays. J Bacteriol 189, 1505-1513.

Rosas-Magallanes, V., Stadthagen-Gomez, G., Rauzier, J., Barreiro, L. B., Tailleux, L., Boudou, F., Griffin, R., Nigou, J., Jackson, M. \& other authors (2007). Signature-tagged transposon mutagenesis identifies novel Mycobacterium tuberculosis genes involved in the parasitism of human macrophages. Infect Immun 75, 504-507.

Said-Salim, B., Mostowy, S., Kristof, A. S. \& Behr, M. A. (2006). Mutations in Mycobacterium tuberculosis Rv0444c, the gene encoding anti-SigK, explain high level expression of MPB70 and MPB83 in Mycobacterium bovis. Mol Microbiol 62, 1251-1263.

Sassetti, C. M. \& Rubin, E. J. (2003). Genetic requirements for mycobacterial survival during infection. Proc Natl Acad Sci U S A 100, 12989-12994. 
Schnappinger, D., Ehrt, S., Voskuil, M. I., Liu, Y., Mangan, J. A., Monahan, I. M., Dolganov, G., Efron, B., Butcher, P. A. \& other authors (2003). Transcriptional adaptation of Mycobacterium tuberculosis within macrophages: insights into the phagosomal environment. J Exp Med 198, 693-704.

Singh, A., Jain, S., Gupta, S., Das, T. \& Tyagi, A. K. (2003). mymA operon of Mycobacterium tuberculosis: its regulation and importance in the cell envelope. FEMS Microbiol Lett 227, 53-63.

Sirakova, T. D., Thirumala, A. K., Dubey, V. S., Sprecher, H. \& Kolattukudy, P. E. (2001). The Mycobacterium tuberculosis pks2 gene encodes the synthase for the hepta- and octamethyl-branched fatty acids required for sulfolipid synthesis. J Biol Chem 276, 16833-16839.

Smith, N. H., Kremer, K., Inwald, J., Dale, J., Driscoll, J. R., Gordon, S. V., van Soolingen, D., Hewinson, R. G. \& Smith, J. M. (2006). Ecotypes of the Mycobacterium tuberculosis complex. J Theor Biol 239, 220-225.

Stermann, M., Sedlacek, L., Maass, S. \& Bange, F. C. (2004). A promoter mutation causes differential nitrate reductase activity of Mycobacterium tuberculosis and Mycobacterium bovis. J Bacteriol 186, 2856-2861.

Stewart, G. R., Wernisch, L., Stabler, R., Mangan, J. A., Hinds, J., Laing, K. G., Young, D. B. \& Butcher, P. D. (2002). Dissection of the heat-shock response in Mycobacterium tuberculosis using mutants and microarrays. Microbiology 148, 3129-3138.

Sulzenbacher, G., Canaan, S., Bordat, Y., Neyrolles, O., Stadthagen, G., Roig-Zamboni, V., Rauzier, J., Maurin, D., Laval, F. \& other authors (2006). LppX is a lipoprotein required for the translocation of phthiocerol dimycocerosates to the surface of Mycobacterium tuberculosis. EMBO J 25, 1436-1444.

van Soolingen, D., de Haas, P. E., Haagsma, J., Eger, T., Hermans, P. W., Ritacco, V., Alito, A. \& van Embden, J. D. (1994). Use of various genetic markers in differentiation of Mycobacterium bovis strains from animals and humans and for studying epidemiology of bovine tuberculosis. J Clin Microbiol 32, 2425-2433.

Walters, S. B., Dubnau, E., Kolesnikova, I., Laval, F., Daffe, M. \& Smith, I. (2006). The Mycobacterium tuberculosis PhoPR twocomponent system regulates genes essential for virulence and complex lipid biosynthesis. Mol Microbiol 60, 312-330.

Weeks, D. L., Eskandari, S., Scott, D. R. \& Sachs, G. (2000). A H ${ }^{+}$gated urea channel: the link between Helicobacter pylori urease and gastric colonization. Science 287, 482-485.

Edited by: J. Parkhill 